\title{
Organizational Commitment Can Improve Compliance of Blood Transfusion Procedure
}

Edi Murwani, Stefanus Supriyanto, Suharto

Faculty of Public Health, University of Airlangga, Surabaya, Indonesia

\begin{tabular}{l} 
Article Info \\
\hline Article history: \\
Received Jan 5, 2016 \\
Revised Mar 23, 2016 \\
Accepted May 20, 2016 \\
\hline
\end{tabular}

\section{Keyword:}

Blood transfusion procedures

Compliance

Midwives

Nurses

Organizational commitment

\section{Corresponding Author:}

Edi Murwani,

Faculty of Public Health,

Airlangga University, Surabaya

East Java, Indonesia.

Email: edimurwani@gmail.com

\begin{abstract}
The purpose of this research was to improve compliance of nurses and midwives on blood transfusion procedures through increased organizational commitment. The study used observational analytic with cross sectional approach. There were 156 nurses and midwives who meet the inclusion and exclusion criteria agreed to be participated as respondents and 46 observers agreed involved in the collection of data through informed consent. The sampling technique was simple random sampling. Data instrument collectors in the form of checklists and questionnaires. Analysis of the data used in the form of descriptive analysis, correlation, and Structural Equation Modeling (SEM). Based on the findings of a new model, a model compliance nurses and midwives on blood transfusion procedures, organizational commitment can improve compliance procedure of blood transfusion if affective commitment and normative commitment improved.
\end{abstract}

Copyright (C) 2016 Institute of Advanced Engineering and Science. All rights reserved.

\section{INTRODUCTION}

Organizational commitment is (1) a strong desire to remain as members of any particular organization; (2) the desire to strive suit the organization; and (3) certain confidence and acceptance of the values and goals of the organization [1]. Compliance of nursing personnel in blood transfusion procedure was rudimentary. It was caused near-miss and adverse events in blood transfusions with the impact of morbidity and mortality [2].

Death caused by transfusion reactions occur 1 (one) per 600.000 cases. Like an iceberg phenomenon, near-miss and adverse events happen greater. Incorrect Blood Component Transfused (IBCT) caused adverse events. Adverse events was reported that lin 15.000 transfusions [3]-[4] up to 1 in 14.000 transfusions [5]; while the near-miss occurred in about 1 in 1.000 transfusions [3], as well as Linden et al in Adibi et al (2012), reported that near-miss events greater incidence, compared with deaths caused by reaction transfusion, that occurred 1/600.000 cases, although the near-miss events were not known how the frequency [4]. Thus, compliance of nursing personnel in blood transfusion procedure completely (100\%) was necessary to support patient safety.

The problem is low compliance of nursing personnel in the blood transfusion procedure at the hospital has an average value of $81.02 \%$ or in the medium category, has not been $100 \%$ or rudimentary [6]. In an effort to increase compliance of nursing personnel in blood transfusion procedures found a new model, a model compliance of nursing personnel in blood transfusion procedures. Based on the model, it revealed that one of the factors that influences to compliance of nursing personnel in blood transfusion procedure is organizational commitment [7]. The problem of organizational commitment has negative effect significantly on compliance of nursing personnel in the blood transfusion procedure [7]. It means that the higher 
organizational commitment decreasing compliance of nurses and midwives in the blood transfusion procedures. So that the formulation of the problem of this research is as follows. Can organizational commitment improve compliance of nurses and midwives' blood transfusion procedure to support patient safety?

\section{RESEARCH METHOD}

The design of this study was an analytic correlation with cross sectional approach. The study populations were nurses and midwives in the Inpatient I (Medicine and Stroke Unit), Inpatient II (Medicine Surgery), Inpatient III (Obstetrics \& Gynecology) and Anesthesi \& Reanimation Installation, in one of type A Education Hospital in Indonesia in April to July 2013. The populations were 410 people [8]. Target populations were 364 people, and not target populations were 46 people.

Samples of this dissertation were nurses and midwives who met the inclusion criteria: (1) implementing nursing/midwifery; (2) carry out a blood transfusion in adult patients. (3) the implementation of the observations: (a) beginning of the program a doctor, (b) blood sampling, (c) sending blood samples to the Blood Bank/UTD or others hospital, (d) acceptance of the blood of Blood Bank/UTD or others hospital, (e) preparation to enter into the patient's blood, (f) the implementation of blood entering into the patient until the first pumpkin finished; (4) one respondent observed one time. Exclusion criteria: (1) the head of the infirmary, the deputy head of the treatment room and head room in case of hospitalization; (2) blood transfusion pumpkin into two and so on. A large sample of 156 people, sampling techniques was simple random sampling.

Instruments data were questionnaire and checklist. Based on the theory that supports structured grating instruments then consulted to experts (promoters and co-promoter) to fulfill content validity and construct validity. Furthermore, the questionnaire of organizational commitment made edits to the Indonesian Department of the Faculty of Letters, State University of Malang to conform to the rules of grammar and easily understood by the layman. Statistical validity test used SPSS 11.5, with Pearson Product Moment correlation technique, the item-total correlation by measuring the correlation score of each of the questions/statements with a score of questions/statements as a whole. The significance level of 0.001 with a mark ** and the significance level of 0.05 with a * [9].

Reliability test were statistically analyzed by Cronbach Alpha [10]. The questionnaire said to be reliable, if the value of Cronbach Alpha $\geq 0,60$ [9]. To determine the feasibility of the research instruments that can be analyzed further conducted exploratory factor analysis. According to Santoso Singgih (2004) standard used is the value of the Kaiser-Meyer-Olkin Measure of Sampling Adequacy (KMO) $>0.5$ with a significance far below $0.05(0.000<0.05)[11]$.

Organizational commitment questionnaire prepared by modification of the concept of organizational commitment Meyer \& Allen [12]. Hospital nursing staff express of concern for hospitals and success and sustainable progress. Organizational commitment measured from: (1) affective commitment, (2) normative commitment and (3) continuance commitment. Questionnaires affective commitment is an emotional attachment to an assessment of the nursing staff in hospitals, identification, and involvement in the activities of the hospital. Questionnaires normative commitment is an emotional attachment to an assessment of the nursing staff at the hospital by feeling obliged to keep working at the hospital had to be so; and such action is the right thing. Questionnaires of continuance commitment is an emotional attachment to an assessment of the hospital nursing staff based on considerations loss if out of the hospital, such as loss of seniority on promotion or benefit. Measurement by performing the above-mentioned questionnaire that uses semantic scale deferensial 10 points to assess the statements ranging from strongly disagree points 1 sd 10 points strongly agree [13].

Checklist compliance nursing staff on the procedure of blood transfusion consists of checklist procedures: (1) blood sampling, (2) blood samples delivery to the Blood Bank Hospital, (3) acceptance of the blood from Blood Bank Hospital, (4) preparation to insert the blood to the patients, (5) the implementation of the insert blood to the patients. Compliance measured by direct observation. Evaluation of questionnaires and checklists using rates which compare the acquisition of scores compared with the total score [14], with the expected outcomes in the form of a percentage (\%). Then categorized into a perfect $(100 \%)$, high $(>90 \%-<$ $100 \%)$, moderate $(80-90 \%)$, low $(<80 \%)$, based on modifications to the compliance of financial management [15].

In the first stage observer who had signed informed consent, in every room observing the process of blood transfusion to the respondents (who had chosen randomly). The timing of observation was also determined randomly by the presence of observers, the respondent, and the patients who underwent blood transfusions. The next stage after all respondents completed observed, after respondents signed informed consent, the respondents filled out questionnaires.

IJPHS Vol. 5, No. 2, June 2016 : 183-192 
The data were analyzed using descriptive, Pearson Product Moment, and SEM. Descriptive was used to analyse description of organizational commitment and compliance of nurses and midwives in blood transfusion procedure. Pearson Product Moment Correlation analysed the relationship between organizational commitment indicator and compliance indicator. SEM with Lisrel 8.30 program analysed the relationship between variables in order to find a model compliance of nurses and midwives in the blood transfusion procedure.

\subsection{Research Ethics}

This study had been complied research ethics, based on (a) Certificate of escaped examine ethics of Health Research Ethics Committee of the Faculty of Public Health, Airlangga University. The dated February 5, 2013 with number: $20 \mathrm{KEPK}$; (b) Then had been permitted the study of the Director dr. Saiful Anwar Malang Hospital with numbers: 070/2529/302/2013 dated March 22, 2013; (c) approved of the 46 observers through informed consent, and (d) approved of 156 respondents through the informed consent.

\section{RESULTS AND ANALYSIS}

\subsection{Organizational Commitment Nurses and Midwives}

Organizational commitment was a latent variable that measured by the level of subvariable affective commitment, normative commitment, continuance commitment nurses and midwives. It was presented in Table 1.

Table 1. Organizational Commitment of Nurses and Midwives in Hospital $(\mathrm{n}=156)$

\begin{tabular}{|c|c|c|}
\hline Indicator \& Sub Indicator & Average Value & Category \\
\hline \multicolumn{3}{|l|}{ Affective Commitment } \\
\hline The desire to stay in the hospital because of the love & $86.00 \%$ & Medium \\
\hline The significance hospital & $87.00 \%$ & Medium \\
\hline \multicolumn{3}{|l|}{ Normative Commitment } \\
\hline Heavy feeling to leaving the hospital & $84.00 \%$ & Medium \\
\hline Keep working in hospitals as a place to learn and get a job first & $86.00 \%$ & Medium \\
\hline \multicolumn{3}{|l|}{ Continuance Commitment } \\
\hline $\begin{array}{l}\text { The idea that it would be better if someone was still working in the organization throughout } \\
\text { his/her career }\end{array}$ & $74.00 \%$ & Low \\
\hline The desire to keep working at the hospital to participate in developing a career and hospitals & $86.00 \%$ & Medium \\
\hline Average Value & $80.00 \%$ & Medium \\
\hline
\end{tabular}

Based on table 1, it can be concluded that the organizational commitment of nurses and midwives was not perfect $(100.00 \%)$, still in the medium category $(84.50 \%)$. This was due to a mean value of affective commitment supported in the medium category $(87.00 \%)$, normative commitment in the medium category $(86.50 \%)$, and the continuance commitment in the medium category $(80.00 \%)$. In detail were presented in Figure 1.

\section{Average Value}

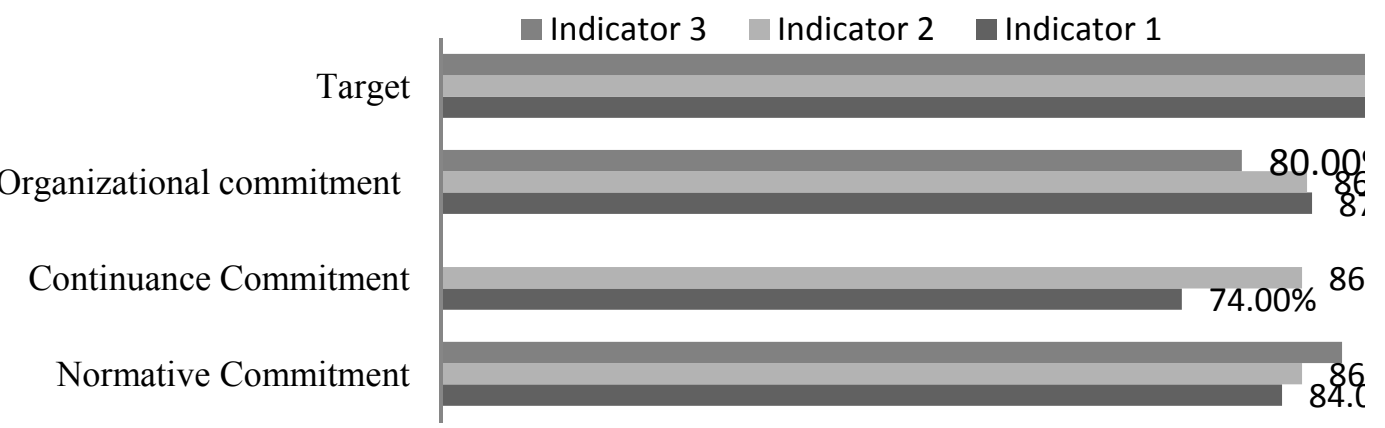

Figure 1. Average Value of Organizational Commitment of Nurses and Midwives at the Hospital $(n=156)$ 


\subsection{Compliance of Nurses and Midwives on the Blood Transfusion Procedure}

Compliance of nurses and midwives on the blood transfusion procedure measured from the compliance of (1) blood sampling procedure, (2) blood samples delivery to the Blood Bank Hospital, (3) blood admission from Blood Bank Hospital, (4) blood insert preparation, (5) blood insert implementation. It was not perfect or in the medium category $(78.72 \%)$. It was contributted from the value of the compliance of sampling procedure in the low category (76.19\%), compliance of blood admission from Blood Bank Hospital in the low category (79.82\%), compliance of blood insert implementation into the patient in the low category $(72.16 \%)$, although compliance of blood sample delivery to Blood Bank Hospital in the medium category $(85.08 \%)$ and compliance blood insert preparation in the medium category $(80.30 \%)$. The average values were presented in Figure 2.

\section{Target \\ C. Blood Transfusion Procedure \\ C. Blood Insert Implementation Procedure \\ C. Blood Insert Preparation Procedure \\ C. Blood Admission Procedure \\ C. Blood Sample Delivery Procedure \\ C. Blood Sampling Procedure}

Figure 2. The Average Value of Compliance of Nurses and Midwives in the Blood Transfusion Procedure

$$
(\mathrm{n}=156)
$$

\subsection{Influence of organizational commitment indicators with indicators of compliance nurses and midwives in the blood transfusion procedure}

Table 2 showed each organizational commitment and compliance indicator has significant influences either. Indicator of organizational commitment that affected compliance indicator was only continuance commitment. It had negative effect significantly on the blood insert preparation procedure.

Table 2. Influence of Organizational Commitment Indicator to Compliance of Nurses and Midwives in the Blood Transfusion Procedure Indicator $(n=156)$

\begin{tabular}{|c|c|c|}
\hline Influence & Correlation Coefisien & Conclusion \\
\hline Affective commitment & $0.796^{* *}$ & Significant \\
\hline Eontinuance commitment & $0.616^{* *}$ & Significant \\
\hline Normative commitment & $0.689 * *$ & Significant \\
\hline Eompliance of blood sampling & -0.101 & Not significant \\
\hline Eompliance of blood samples delivery & -0.108 & Not significant \\
\hline Eompliance of blood acceptance & 0.026 & Not significant \\
\hline Compliance of blood insert preparation & -0.052 & Not significant \\
\hline Compliance of blood insert implementation & 0.008 & Not significant \\
\hline Eompliance of blood sampling & -0.140 & Not significant \\
\hline Oompliance of blood samples delivery & -0.099 & Not significant \\
\hline Eompliance of blood acceptance procedure & -0.014 & Not significant \\
\hline Sompliance of blood insert preparation & -0.094 & Not significant \\
\hline Sompliance of blood insert implementation & -0.031 & Not significant \\
\hline Compliance of blood sampling & -0.150 & Not significant \\
\hline Compliance of blood samples delivery & -0.126 & Not significant \\
\hline Compliance of blood acceptance & -0.070 & Not significant \\
\hline Compliance of blood insert preparation & $-0.160 *$ & Significant \\
\hline Compliance of blood insert implementation & -0.141 & Not significant \\
\hline \multicolumn{3}{|l|}{ Compliance Procedure of } \\
\hline Blood sampling $\longrightarrow$ & $0.631 * *$ & Significant \\
\hline Blood sampling & $0.545^{* *}$ & Significant \\
\hline Blood insert preparation & $0.777 * *$ & Significant \\
\hline Blood sampling $\longleftrightarrow$ Blood insert implementation & $0.715^{* *}$ & Significant \\
\hline Blood samples delivery $\longleftrightarrow$ Blood acceptance & $0.543 * *$ & Significant \\
\hline Blood samples delivery & $0.651 * *$ & Significant \\
\hline Blood samples delivery $\longleftrightarrow$ Blood insert implementation & $0.538 * *$ & Significant \\
\hline Blood insert preparation & $0.548 * *$ & Significant \\
\hline Blood acceptance $\longrightarrow$ Blood insert implementation & $0.538 * *$ & Significant \\
\hline Blood insert preparation $\longrightarrow$ Blood insert implementation & $0.695 * *$ & Significant \\
\hline
\end{tabular}

IJPHS Vol. 5, No. 2, June 2016: $183-192$ 
Table 2 concluded that (1) the affective commitment and normative commitment did not directly affect compliance of (a) blood sample taking, (b) sending of blood samples, (c) blood acceptance, (d) blood insert preparation, and (e) blood insert implementation. (2) compliance of nurses and midwives in blood insert preparation was not only influenced by the commitment continuance, but it was influenced by compliance of nurses and midwives in the procedure of blood sampling, blood sample delivery into Blood Bank Hospital, and blood acceptance from the Blood Bank Hospital also. It had the significant positive effect. (3) compliance of blood insert preparation influenced compliance of blood insert implementation; although compliance of blood insert implementation was influenced by compliance of (a) blood sampling, (b) sending blood samples to the Blood Bank Hospital and blood acceptance from Blood Bank Hospital. It was presented in Figure 3.

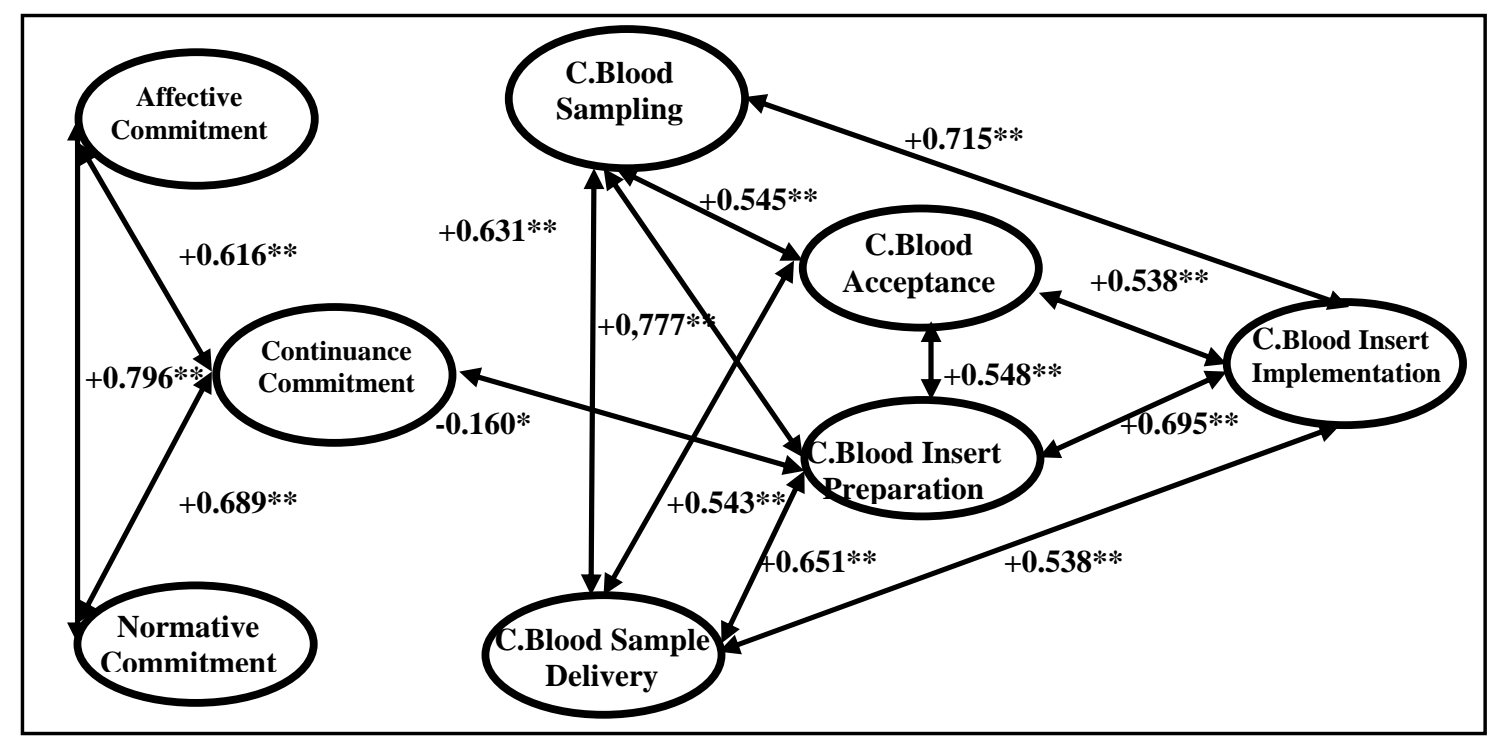

Figure 3. Influence of Organizational Commitment Indicator to Compliance of Nurses and Midwives on the Blood Transfusion Procedure Indicator $(n=156)$

\subsection{The results of the analysis of Structural Equation Modeling (SEM)}

\subsubsection{Confirmatory Factor Analysis (CFA) of Organizational Commitment of Nurses and Midwives}

Organizational commitment (Comorg) was a two level of latent variable. It was measured from affective commitment (Affctive) which had 2 indicators, normative commitment (Nrmative) which had three indicators, and continuance commitment (Cntinuanc) which had two indicators. Indicator of affective commitment was (1) the desire to stay in the hospital because of the love (LOVE), (2) the significance hospital (MEAN). Indicator of normative commitment was (1) heavy feeling to leaving the hospital (FEEL), (2) keep working in hospitals as a place to learn and get a job first (FRSTJOB), (3) complying with rules and regulations are moral responsibility (MORAL). Indicator of continuance commitment was (1) the idea that it would be better if some one is still working in the organization throughout his career (ONEORG), (2) the desire to keep working in hospital to participate in developing a career and hospitals (CAREER). Results of confirmatory factor analysis were presented in Figure 4. 


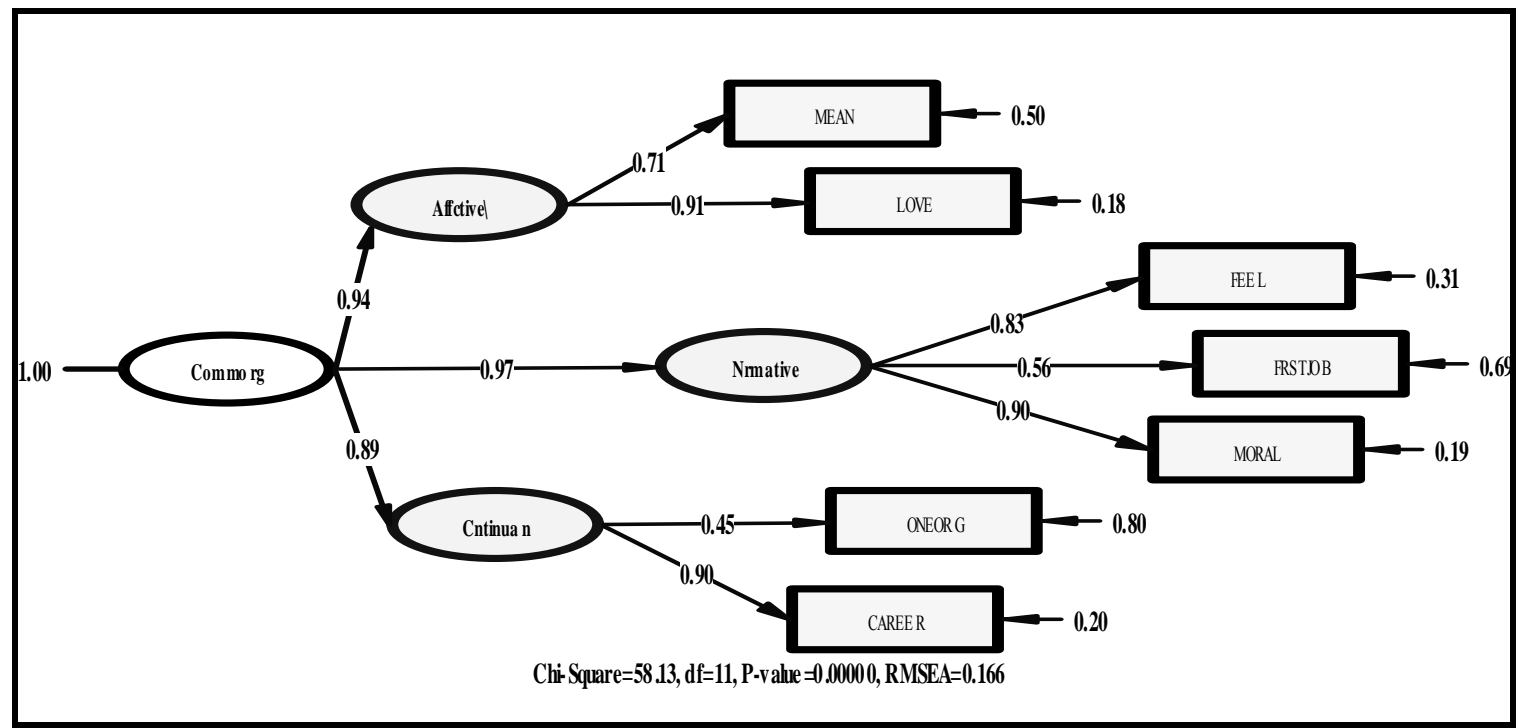

Figure 4. Confirmatory Factor Analysis Organizational Commitment of Nurses and Midwives at the Hospital

$$
(\mathrm{n}=156)
$$

Based on Figure 3, value of standardize loading factor $\geq 0.50$ meant that all indicators and subindicators were valid and reliable. Thereby, the components of organizational commitment were affective commitment, normative commitment, and continuance commitment.

\subsubsection{CFA of Compliance of Nurses and Midwives on Blood Transfusion Procedure}

Compliance of nurses and midwives on the blood transfusion procedures measured the compliance of p: blood sampling (SAMPLING), sending blood samples to the Blood Bank Hospital (SEND), blood acceptance from Blood Bank Hospital (ACCEPT), blood insert preparation (PREPARE), blood insert implementation (INSERT). Result of confirmatory factor analysis was presented in Figure 5

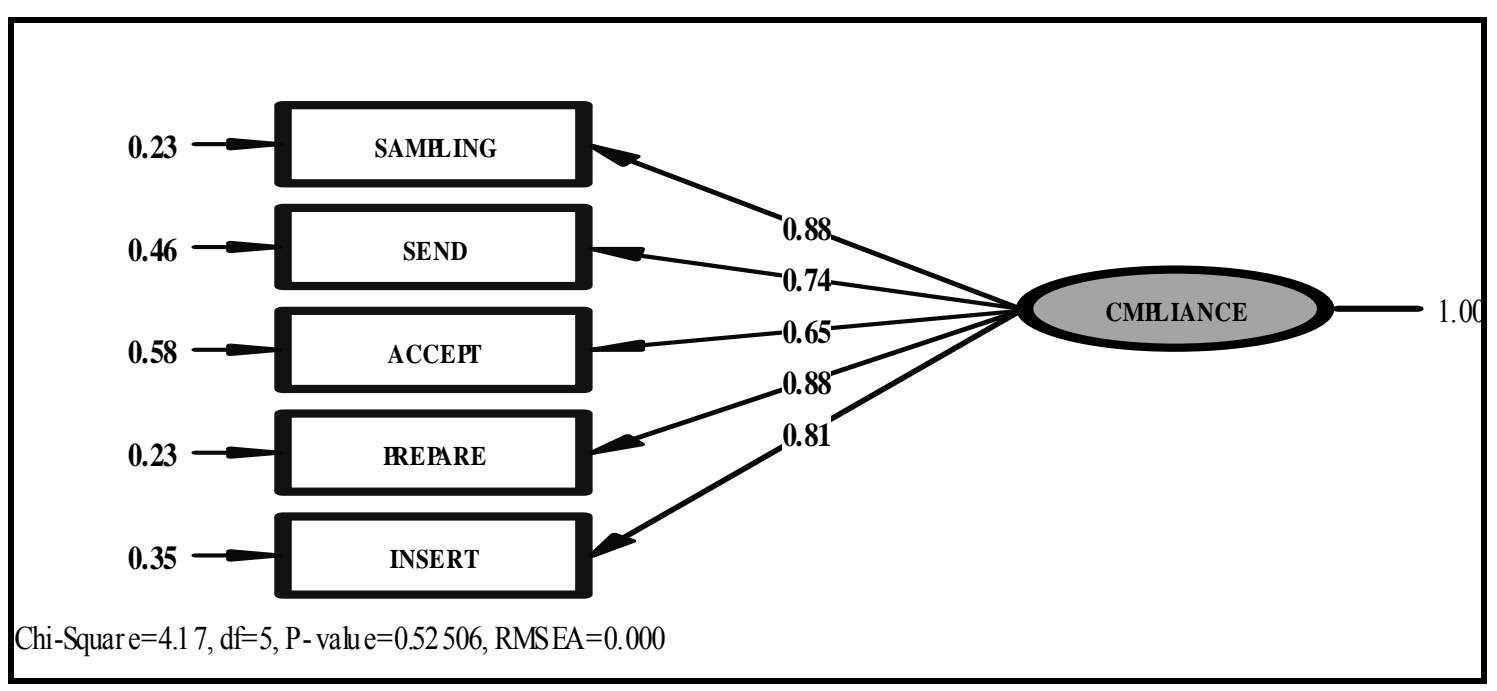

Figure 5. Confirmatory Factor Analysis Compliance of Nurses and Midwives on the Blood Transfusion Procedur at the Hospital $(\mathrm{n}=156)$

Figure 5 showes that the value of standardize loading factor of each indicator was $>0.50$. The meaning was valid and reliable; Thus, the variable component compliance procedure of blood transfusion was compliance procedure: (1) blood sampling (SAMPLING), (2) sending blood samples to the Blood Bank 
Hospital (SEND), (3) blood acceptance from the Blood Bank Hospital (ACCEPT), (4 ) blood insert preparation (PREPARE) and (5) blood insert implementation (INSERT).

\subsubsection{Analysis of Structural Model (Full SEM)}

Based on analysis structural equation modeling a new model was found. The model was a compliance model of nurses and midwives in the blood transfusion procedure. It was presented in Figure 6.

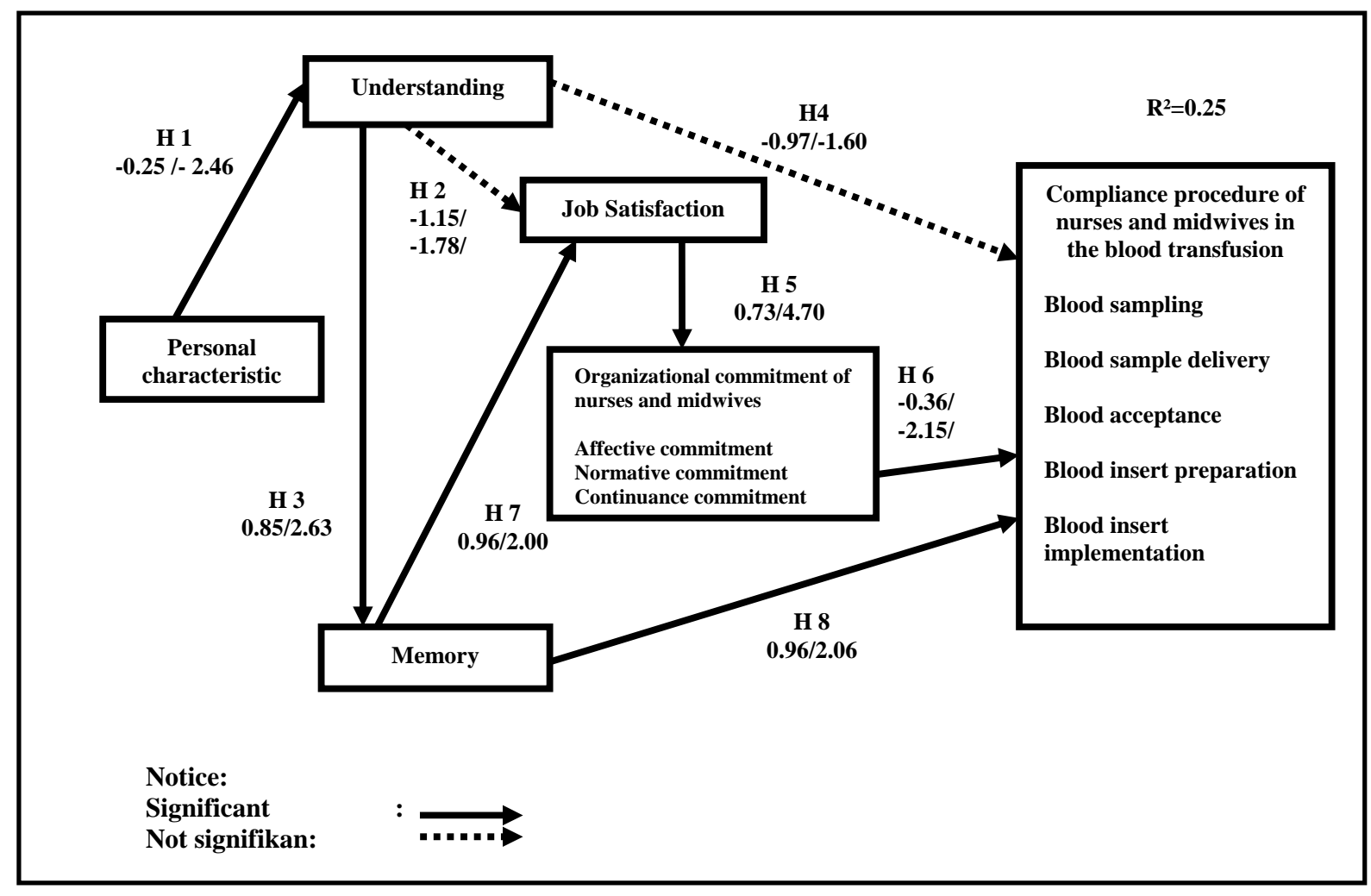

Figure 6. Compliance Model of Nurses and Midwives in the Blood Transfusion Procedure

Figure 5 showed that (1) Compliance of nurses and midwives in the blood transfusion procedure was affected by: (a) Understanding of nurses and midwives in the instruction of the leader to carry out of blood transfusion procedure. (b) Memory of nurses and midwives about blood transfusion procedure; (c) Job satisfaction of nurses and midwives; (d) Organizational commitment of nurses and midwives, with regard (e) Personal characteristics of nurses and midwives. (2) Personal characteristics of nurses and midwives paths to compliance of nurses and midwives in the blood transfusion procedure through the understanding and memory were stronger than job satisfaction and organizational commitment paths. (3) Contributions effect of variables simultaneously to compliance by $25 \%$.

Based on the analysis of the structural model of organizational commitment, nurses and midwives had significant negative effect on the compliance in the blood transfusion procedure. Based on table 2, continuance commitment had significant negative effect on compliance nursing personnel in preparation to enter into the patient's blood. In this dissertation, continuance commitments of nurses and midwives were been influenced by the personal characteristics of nurses and midwives, continuance commitments had an average value in the medium category $(80.00 \%)$. This was due to supported by an average value of the opinion of nurses and midwives of the statement was follows. (1) It would be better if some one was still working in the organization throughout his/her career (in the low category); (2) The desire to remain working at the hospital to participate in developing a career (in the medium category). Results of this study supported A Three-Component Model of Organizational Commitment, which stated that the commitment continuance had no effect or a significant negative effect on work behaviors (attendance, OCB and performance), if it was affected by the personal characteristics, alternatives, and investments. In contrast, affective commitment of nurses and midwives had not been affected to the compliance of nurses and midwives in the blood transfusion procedure [16]. It did not supported Meyer John P., et al. (2002), which stated that affective 
commitment had positive effect significantly on work behaviors (attendance, OCB and performance). Affective commitment had influenced to the compliance of nurses and midwives if it had influenced by personal characteristic and working experience, there were supported by job satisfaction, job involvement, and occupational commitment; because of affective commitment in this study was only influenced by job satisfaction. Job involvement and occupational commitment were not investigation yet. Similarly, the results of this study stated that the normative commitment did not affect the compliance of nurses and midwives in the blood transfusion procedure. It did not support Meyer John P., et al. (2002), which stated that normative commitment had significant positive effect on work behaviors (attendance, OCB and performance) if it was influenced by personal characteristics, socialization experiences, and organizational investment [16]. In this study normative commitment was influenced by personal characteristics of nurses and midwives through the understanding of nurses and midwives in the leaders' instruction to carry out the blood transfusion procedure and memory of nurses and midwives about blood transfusion procedure, as well as job satisfaction, while socialization experiences, and organizational investment had not been studied.

\section{CONCLUSION}

Compliance of nurses and midwives on the blood transfusion procedure had not been perfect in the moderate category. It was measured from compliance of nurses and midwives in the procedure of (1) blood sampling, (2) blood sample delivery to the Blood Bank Hospital, (3) acceptance of the blood from Blood Bank Hospital, (4 ) blood insert preparation, (5) blood insert implementation. Perfect compliance prevented near-miss and adverse events, so as to supported patient safety program. Therefore, compliance of nurses and midwives on blood transfusion procedures needed to be improved.

The organizational commitment of nurses and midwives (measured from affective commitment, normative commitment, and continuance commitment), had a mean value in the medium category; organizational commitment of nurses and midwives had significant negative effect on the compliance of nurses and midwives in the blood transfusion procedure. But the organizational commitment of nurses and midwives can improve compliance nurses and midwives in the blood transfusion procedure if affective commitment and normative commitment of nurses and midwives improved.

Affective commitment and normative commitment of nurses and midwives needed to be upgraded to support increased compliance of nurses and midwives on blood transfusion procedures in order to support patient safety.

Efforts to increase affective commitment of nurses and midwives are as follows: (1) increasing the personal characteristics of nurses and midwives (increase understanding of nurses and midwives in the leaders' instruction to carry out blood transfusion procedure and memory of nurses and midwives about blood transfusion procedure) by way of the implementation of knowledge management. Knowledge management consists of : (a) the establishment of committees blood transfusion hospitals, (b) preparation of training modules blood transfusion, (c) carrying out the training of blood transfusion on officers who carry out the procedure of blood transfusion, (d) an increase in work culture committee blood transfusion; (2) monitoring and evaluation of patient safety blood transfusion through the recording of reporting that is accompanied by a program of repairs \& follow-up; (3) an increase in job satisfaction (increase motivator factors and maintenance factors) by: (a) the evaluation of performance and providing feedback, (b) a program of recognition and promotion, (c) an increase in the working relationship among employees, (d) training supervision of the head of the chamber, (e) improvement of working conditions, (f) evaluation of hospital policy, (g) the evaluation of salary, and (h) an increase in job security; (4) socialization experiences (insert socialization program policies and procedures for blood transfusions in orientation program new nursing personnel (nurses and midwives) and (5) organizational investment (insert compliance nurses and midwives on blood transfusion procedures into program remuneration).

Efforts to improve the normative commitment of nurses and midwives are as follows: (1) The increase in job satisfaction involved the increase of motivator factors and maintenance factors. It is increased by ways of (a) evaluation of performance and providing feedback; (b) a program of recognition and promotion; (c) an increase in the working relationship among employees; (d) supervisory training for head of ward; (e) improvement of working conditions; (f) evaluation of hospital policy; (g) the evaluation of salary; and (h) an increase in job security. (2) The increase in job involvement is had been done by ways of implementing the program involvement of employees. It is in improvement programs relating to the safety of the patients that undergoes blood transfusions through the activities of the Quality Control Circle (QCC), and (3) an increase in occupational commitment or work commitments or professional commitment. It is recognized as a profession (salary based on education nursing staff /nurses and midwives) and the profession is used for life.

IJPHS Vol. 5, No. 2, June 2016:183-192 


\section{ACKNOWLEDGEMENTS}

Authors expressed thanks and high appreciation to the mother, husband, children, grandchild, and family for their prayers, moral, and material supported. Then to a large family of dr. Saiful Anwar Malang Hospital, East Java, Indonesia; in particular nurses and midwives and all persons who supported this research. The Kendedes Foundation, Malang, East Java, Indonesia, which had supported the funding of this research. The presented in this scientific article were had resulted of the authors'research, there were no had intervented of any organization.

\section{REFERENCES}

[1] F. Luthans, "Organizational Behaviour," tenth Ed., Yogyakarta, Andi Publisher, 2006.

[2] B. Maggs, et al., "Annual Report SHOT (Serious Hazards of Transfusion)," Manchester, Manchester Blood Center Plymooth Grove, 2012. www.shotuk.org.

[3] E. C. Vamvakas \& M. A. Blajchman, "Transfusion-related mortality: the ongoing risk of allogenic blood transfusion and the available strategies for their prevention," Blood, vol/issue: 13(16), pp. 3406-3417, 2009.

[4] A. Hossein, et al., "Root-cause Analysis of a Potentially Sentinel Transfusion Event; Lessons for Improvement of Patient Safety," Tehran University of Medical Sciences, Acta Medica Iranica, vol/issue: 50(9), pp. 624-631, 2012.

[5] "Clinical Guide to Transfusion," Canadian Blood Services, 2007.

[6] Murwani E., "Factors that Influence the Implementation of the Director on Policy about Blood Transfusion Procedure in dr. Saiful Anwar Hospital," Thesis, Post Graduate Program, University of Brawijaya, Malang, 2008.

[7] Murwani E., "Compliance Model of Nursing Personnel on the Blood Transfusion Procedure at the Hospital," Dissertation, Doctoral Studies Program of Health Sciences, Faculty of Public Health, Airlangga University, Surabaya, Indonesia, 2015.

[8] "Division of Nursing," dr. Saiful Anwar Hospital, Malang, 2013.

[9] P. B. Santoso, "Statistical Analysis with Microsoft Excel and SPSS," Yogyakarta, Andi, 2005.

[10] Kusnendi, "Structural Equation Models One and Multigroup Samples with Lisrel," Bandung, Alfabeta, 2008.

[11] S. Singgih, "A SPSS Multivariate Statystic Exercise Book," Jakarta, PT Elexmedia Komputindo Gramedia Group, pp. $242-260,2004$.

[12] Meyer J. P. \& Allen N. J., "TCM Employee Commitment Survey Academic Users Guide," Department of Psychology, The Univesity of Western Ontario, 2004.

[13] Ridwan \& Kuncoro E. A., "How to Use and Interpret the Path Analysis," Bandung, Alfabeta, 2006.

[14] S. Supriyanto \& N. A. Damayanti, "Planning and Evaluation," Ed.I, Surabaya, Airlangga University Press, 2007.

[15] "Financial Management Annual Compliance Report fo the year 2010-2011," Melbourne: Departement of Treasure and Finance State Government Victoria, Australia, 2012.

[16] Meyer J. P., et al., "Affective, Continuance, and Normative Commitment to the Organization: A Meta-analysis of Antecedents, Correlated, and Consequences," Journal of Vocational Behaviour, vol. 61, pp. 20-52, 2002.

\section{BIOGRAPHIES OF AUTHORS}

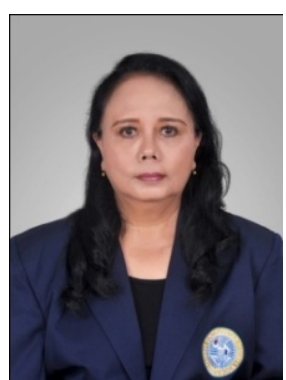

\section{Edi Murwani}

Doctoral Candidate, Doctoral Studies Program of Health Sciences, Faculty of Public Health, Airlangga University, Surabaya, Indonesia.

Full Duty of Head Subdivision of Research and Development dr. Saiful Anwar Malang Hospital, East Java, Indonesia. Division expertise of Hospital Management.

Lecturer Program Diploma 3 Midwifery STIKes Kendedes Malang, East Java, Indonesia Chairman of the STIKes Kendedes Malang, East Java, Indonesia

Email: edimurwani@gmail.com

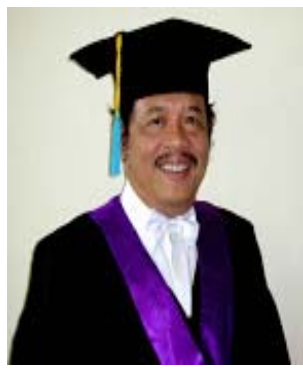

\section{Stefanus Supriyanto}

Professor with expertise Field of Administrative Sciences and Health Policy,

Planning and Evaluation Special Studies, Marketing Management and Quality Management Services, at Airlangga University, Surabaya, East Java, Indonesia. Lecturer Doctoral Studies Program of Health Sciences, Faculty of Public Health, Airlangga University Surabaya, East Java, Indonesia.

Consultant and speaker of Marketing Hospital,Entrepreneurship, Health Insurance, Funding and Budgeting System and the Regional Companion Development of Regional Health System.

Chairman of Masters Program in Health Services Management, Faculty of Public Health, University of Airlangga, Surabaya, East Java, Indonesia.

Email: stefpri49@gmail.com 


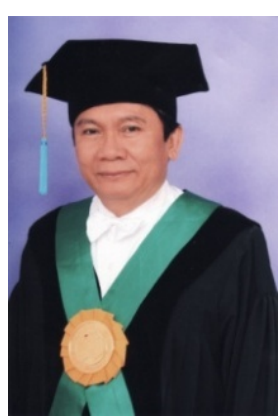

\section{Suharto}

Professor with expertise Field of Medicine in dr. Soetomo, and Airlangga University, Surabaya, Indonesia.

President Director of Tropical Infectious Hospital, Surabaya, East Java, Indonesia. Lecturer Doctoral Studies Program of Health Sciences, Faculty of Public Health, University of Airlangga in Surabaya, East Java, Indonesia. Chairman of the Master of Nursing Science, Faculty of Nursing, University of Airlangga in Surabaya, East Java, Indonesia. Chairman of MKDU PPDS I Medicine Faculty of Medicine, University of Airlangga, East Java, Indonesia. Chairman of the Medical Advisory DPM BPJS, East Java, Indonesia. Stering members of INA Respond Research and Development Committee in cooperation with the United States. Dean of Medicine of Faculty, Nahdlatul Ulama University, Surabaya, Indonesia.

Email: divtropin@yahoo.com 